\title{
New HYDRA Option: Time Histories of Element Pressure with THUG
}

\author{
Rose C. McCallen \\ Barbara T. Kornblum \\ Douglas E. Speck
}

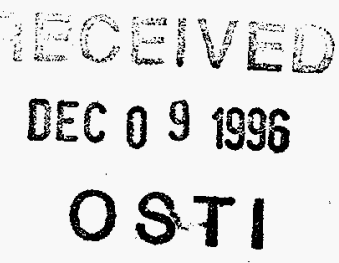

September 26, 1996

This is an informal report intended primarily for internal or limited external distribution. The opinions and conclusions stated are those of the author and may or may not be those of the Laboratory.

Work performed under the auspices of the U.S. Department of Energy by the Lawrence Livermore National Laboratory under Contract W-7405-Eng-48.

\section{DISTRIBUTION OF THIS DOCUMENT IS UNUMTEO}

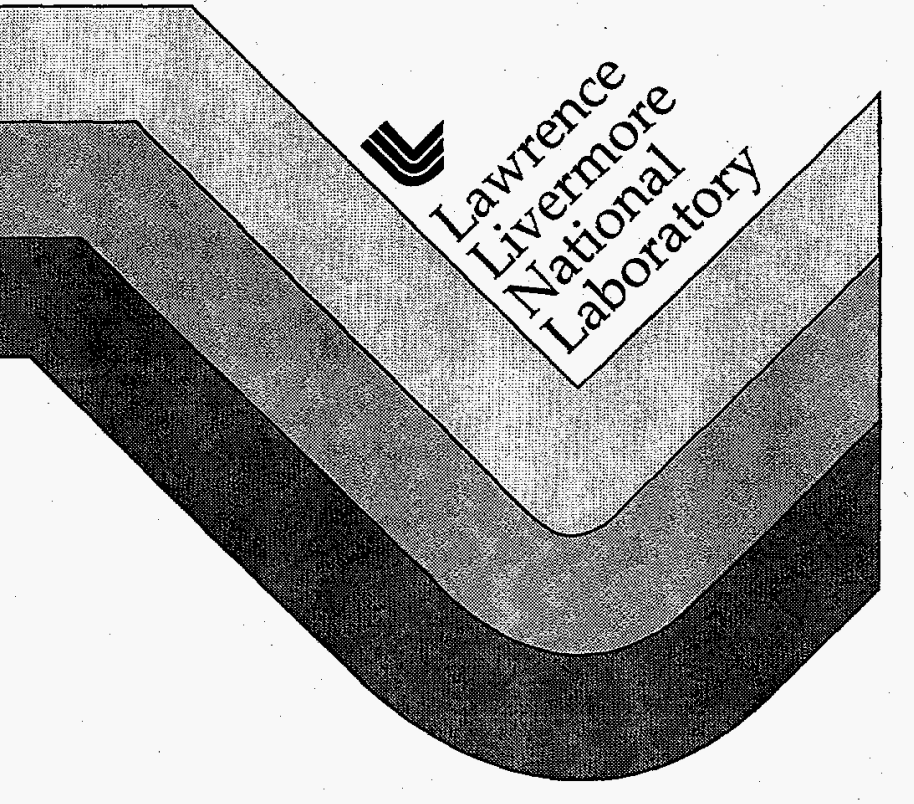


This document was prepared as an account of work sponsored by an agency of the United States Government. Neither the United States Government nor the University of California nor any of their employees, makes any warranty, express or implied, or assumes any legal liability or responsibility for the accuracy, completeness, or usefulness of any information, apparatus, product, or process disclosed, or represents that its use would not infringe privately owned rights. Reference herein to any specific commercial product, process, or service by trade name, trademark, manufacturer, or otherwise, does not necessarily constitute or imply its endorsement, recommendation, or favoring by the United States Government or the University of California. The views and opinions of authors expressed herein do not necessarily state or reflect those of the United States Government or the University of California, and shall not be used for advertising or product endorsement purposes.

This report has been reproduced directly from the best available copy.

Available to DOE and DOE contractors from the

Office of Scientific and Technical Information

P.O. Box 62, Oak Ridge, TN 37831

Prices available from (615) 576-8401, FTS 626-8401

Available to the public from the

National Technical Information Service

U.S. Department of Commerce

5285 Port Royal Rd.,

Springfield, VA 22161 


\section{DISCLAIMIER}

Portions of this document may be illegible in electronic image products. Images are produced from the best available original document. 


\title{
New HYDRA Option: Time Histories of Element Pressure with THUG
}

\author{
Rose C. McCallen, Barbara T. Kornblum, and Douglas E. Speck
}

\subsection{Introduction}

The incompressible Navier-Stokes flow code HYDRA (Christon 1995) has been modified to produce pressure time history databases for both two-dimensional (2D) and three-dimensional (3D) simulations. This report describes the control parameters needed to activate this option in HYDRA. A detailed description of the actual code modifications are included in Appendix A. The generated pressure time history data is formatted for postprocessing with the code THUG.(Speck 1996). A brief description of how to produce pressure time history plots is included here for completeness.

\subsection{Background}

HYDRA uses the Q1P0 element formulation which provides bilinear velocity support in 2D and trilinear support in 3D with piecewise constant pressure. Thus, the solution produces nodal velocities and element centered pressures for evaluation. Originally only nodal velocities were part of the time history edit. We have added the option to produce element pressure time histories in order to enhance data analysis capabilities. Thus, this addition provides a time history edit of element quantities. Further expansion to include the editing of other element quantities (e.g., vorticity, turbulent eddy viscosity) should be fairly straightforward in the future.

\subsection{Pressure Time History Control Parameters in HYDRA}

The control parameters for activating the pressure (element) time history option are patterned after the parameters for the velocity (nodal) time history option (see page 36, Figure 4.1, and page 47 in HYDRA manual or copy of pages included here in Appendix B). The format is

C The elhist-end block defines the time-history elements

elhist number of element blocks

nstep edit interval

st starting number en end number

end 
In the current setup, the edit interval for the element histories (nstep) must be the same as that for the nodal time histories.

\subsection{Plotting Results with THUG}

To accommodate both $2 \mathrm{D}$ and 3D simulation data with the same postprocessing tools, THUG traditionally plots 2D results as shell element data. (For output format information see Procassini 1995.) Fortunately, a flag is written to the output file by HYDRA to signal the THUG code that only a limited number of the shell output parameters are written to the time history file ( 7 instead of the standard 33) so that the $2 \mathrm{D}$ time history output is comparable to that in $3 \mathrm{D}$. Another flag signals THUG that nodal data is excluded. (Nodal data is normally included with each element time history to support strain calculations in solid mechanics problems.) Excluding nodal data further reduces the output by 56 parameters per element for hexahedron data and 28 parameters per element for shell data. In 3D and 2D, the parameter to plot with THUG is 'pressure'.

The steps in plotting pressure time histories with THUG are the following
thug $-\mathbf{i}[<$ path $>]<$ time history root name $>$
to run THUG
gather s starting number-ending number
for shells (2D pressure elements)
gather $\mathbf{h}$ starting number-ending number
for hexahedrons (3D pressure elements)
plot press s starting number-ending number
for shells
plot press h starting number-ending number for hexahedrons

For a more general description of THUG command syntax, refer to the THUG manual.

\section{References}

Christon, M.A. 1995, “HYDRA: A Finite Element Computational Fluid Dynamics Code User Manual”, LLNL UCRL-MA-121344.

Procassini, R.J. 1995, "Description of the Plot and Time History Data Bases Currently Used in the MDG Finite Element Codes”, LLNL internal document.

Speck, D.E. 1996, "THUG: Time Histories from Unstructured Grids User Manual", UCRL-MA124586. 


\section{Appendix A \\ Details of Coding Changes}

The following is a list of modified files with a detailed description of the code changes.
STORAGE
- pointer 57 identified for storage of time history element blocks inls $(2, n b k n l)$.
- pointer 35 in array icntl identified for control variable $n b k n l$ which is the number of element time history blocks.
- pointer 36 in array icntl identified for variable nwnlth which is the number of words for ele- ment time history blocks.
pointers.h - inls added to common block ptrs, dimension statement, and pointer statement.
chkpnt.F - subroutine ckpnt: included element blocks inls in restart file.
- subroutine rstart: reads inls from restart file and allocates memory.
drv2d.F - subroutines fe2d, fead2a, imad2a, p22d, p22dorg, and $p 22 d a b$ : added inls, $p$, rho, and $n b k n l$ to call thnd $2 d$.
drv3d.F - subroutine $f e 3 d, p 23 d, p 23 d o r g$, and $p 23 e$ : added inls, $p$, rho, and $n b k n l$ to call thnd3d.
io.F
- subroutine cntlin: added $n b k n l$.
- subroutine ekoctl: added $n b k n l$.
- subroutine getctl: set default for $n b k n l=0$ and added parse of element time history blocks.
- subroutine getmod: added parse of element time histories, changed call getthb to getthbnd, and added call getthbel.
- subroutine getthbel: added parse of control file for element time histories.
- subroutine getthbnd: name of subroutine change from getthb
- subroutine modctl: added write for element time histories.
- subroutine nsinpt: added output of element time histories as shell elements for $2 \mathrm{D}$ and brick elements for 3D.
- subroutine thnd2d: added write of element data.
- subroutine thnd $3 d$ : added write of element data.
- subroutine wrthnd: added element data. 


\section{Appendix B \\ Pages from HYDRA Manual Describing Input Format}


Analysis Title $\{80$ characters or less $\}$

C A "C" followed by a blank space starts a comment line \{Comments may be enclosed in braces as well\}

$C$ The mesh-end block describes the mesh parameters mesh

...

end

$C$ The analyze-end block describes the analysis parameters

analyze

$\cdots$

end

C The momsol-end block defines the momentum equation solver

momsol

..

end

$C$ The ppesol-end block defines the PPE equation solver ppesol

$\cdots$

end

$C$ The nahist-end block defines the time-history nodes ndhist

$\cdots$

end

elhist

4

:

end

erid

Figure 4.1: A Sample HYDRA Control File 


\subsubsection{Time History Blocks}

Time history nodes may be defined to track primitive nodal variables at a small number of nodes where the interval that the data is recorded at is much smaller than for state data. This type of data is useful for detecting steady-state conditions, and for the evaluation of periodic behavior.

\section{Time History Blocks}

\begin{tabular}{|c|l|}
\hline Keyword & Variable \& Meaning \\
\hline ndhist $n$ & Specify n time history nodes (default: $\mathbf{n}=\mathbf{0})$ \\
st & Starting node number in block. \\
en & Ending node number in block. \\
nstep & Time history output interval (default: $\mathbf{n s t e p = 1 )}$. \\
end & Terminate time history block \\
\hline
\end{tabular}

New input:

\begin{tabular}{ll}
\hline elhist $n$ & Specify $n$ time history elements (default $\mathbf{n = 0}$ ). \\
st & Starting element number in block. \\
en & Ending element number in block. \\
nstep & Time history output interval (must be the same as that for nodal time histories). \\
end & Terminate time history block.
\end{tabular}

